\title{
Front Matter: Volume 8935
}

, "Front Matter: Volume 8935," Proc. SPIE 8935, Advanced Biomedical and Clinical Diagnostic Systems XII, 893501 (6 March 2014); doi:

10.1117/12.2053619

SPIE. Event: SPIE BiOS, 2014, San Francisco, California, United States 


\section{Advanced Biomedical and Clinical Diagnostic and Surgical Guidance Systems XII}

Tuan Vo-Dinh

Anita Mahadevan-Jansen

Warren S. Grundfest

Editors

2-4 February 2014

San Francisco, California, United States

Sponsored and Published by

SPIE 
The papers included in this volume were part of the technical conference cited on the cover and title page. Papers were selected and subject to review by the editors and conference program committee. Some conference presentations may not be available for publication. The papers published in these proceedings reflect the work and thoughts of the authors and are published herein as submitted. The publisher is not responsible for the validity of the information or for any outcomes resulting from reliance thereon.

Please use the following format to cite material from this book:

Author(s), "Title of Paper," in Advanced Biomedical and Clinical Diagnostic and Surgical Guidance Systems XII, edited by Tuan Vo-Dinh, Anita Mahadevan-Jansen, Warren S. Grundfest M.D., Proceedings of SPIE Vol. 8935 (SPIE, Bellingham, WA, 2014) Article CID Number.

ISSN: 1605-7422

ISBN: 9780819498489

Published by

SPIE

P.O. Box 10, Bellingham, Washington 98227-0010 USA

Telephone +1 3606763290 (Pacific Time) · Fax +1 3606471445

SPIE.org

Copyright (C) 2014, Society of Photo-Optical Instrumentation Engineers.

Copying of material in this book for internal or personal use, or for the internal or personal use of specific clients, beyond the fair use provisions granted by the U.S. Copyright Law is authorized by SPIE subject to payment of copying fees. The Transactional Reporting Service base fee for this volume is $\$ 18.00$ per article (or portion thereof), which should be paid directly to the Copyright Clearance Center (CCC), 222 Rosewood Drive, Danvers, MA 01923. Payment may also be made electronically through CCC Online at copyright.com. Other copying for republication, resale, advertising or promotion, or any form of systematic or multiple reproduction of any material in this book is prohibited except with permission in writing from the publisher. The CCC fee code is $1605-7422 / 14 / \$ 18.00$.

Printed in the United States of America.

Publication of record for individual papers is online in the SPIE Digital Library.

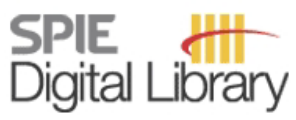

SPIEDigitalLibrary.org

Paper Numbering: Proceedings of SPIE follow an e-First publication model, with papers published first online and then in print and on CD-ROM. Papers are published as they are submitted and meet publication criteria. A unique, consistent, permanent citation identifier (CID) number is assigned to each article at the time of the first publication. Utilization of CIDs allows articles to be fully citable as soon as they are published online, and connects the same identifier to all online, print, and electronic versions of the publication. SPIE uses a six-digit CID article numbering system in which:

- The first four digits correspond to the SPIE volume number.

- The last two digits indicate publication order within the volume using a Base 36 numbering

system employing both numerals and letters. These two-number sets start with 00, 01, 02, 03, 04, $05,06,07,08,09,0 A, 0 B \ldots$. 0Z, followed by 10-1Z, 20-2Z, etc.

The CID Number appears on each page of the manuscript. The complete citation is used on the first page, and an abbreviated version on subsequent pages. Numbers in the index correspond to the last two digits of the six-digit CID Number. 


\section{Contents}

ix Conference Committee

xi Introduction

\section{FLUORESCENCE SYSTEMS}

893504 Fluorescence spectroscopy using indocyanine green for lymph node mapping [8935-3] N. Haj-Hosseini, Linköping Univ. (Sweden); P. Behm, Linköping Univ. (Sweden) and Fachhochschule NordWestschweiz (Switzerland); I. Shabo, Linköping Univ. Hospital (Sweden) and Linköping Univ. (Sweden); K. Wårdell, Linköping Univ. (Sweden)

\section{GLOBAL HEALTH TECHNOLOGIES II}

893509 Rapid transdermal bloodless and reagent-free malaria detection [8935-7]

E. Y. Lukianova-Hleb, K. M. Campbell, P. E. Constantinou, J. Braam, J. S. Olson, R. E. Ware, Rice Univ. (United States); D. S. Sullivan, Johns Hopkins Bloomberg School of Public Health (United States); D. O. Lapotko, Rice Univ. (United States)

8935 OA The study of synchronization of rhythms of microvascular blood flow and oxygen saturation during adaptive changes [8935-9]

A. V. Dunaev, Univ. of Dundee (United Kingdom) and State Univ. Education-ScienceProduction Complex (Russian Federation); V. V. Sidorov, SPE LAZMA Ltd. (Russian Federation); A. I. Krupatkin, Central Research Institute of Traumatology and Orthopaedics (Russian Federation); I. E. Rafailov, S. G. Palmer, S. G. Sokolovski, N. A. Stewart, E. U. Rafailov, Univ. of Dundee (United Kingdom)

8935 OB Dermascope assisted interactive patient interface for multiple reference optical coherence tomography [8935-10]

R. Dsouza, H. Subhash, K. Neuhaus, National Univ. of Ireland, Galway (Ireland); J. Hogan, C. Wilson, Compact Imaging, Inc. (United States); M. Leahy, National Univ. of Ireland, Galway (Ireland) and Royal College of Surgeons (Ireland)

\section{TREATMENT MODALITIES AND IMAGE-GUIDED SURGERY}

8935 OE Optically enhanced blood-brain-barrier crossing of plasmonic-active nanoparticles in preclinical brain tumor animal models [8935-13]

H. Yuan, Duke Univ. (United States); C. M. Wilson, S. Li, Duke Univ. Medical Ctr. (United States); A. M. Fales, Y. Liu, Duke Univ. (United States); G. A. Grant, Duke Univ. Medical Ctr. (United States); T. Vo-Dinh, Duke Univ. (United States) 
8935 OF The Fluostick, a real hand-held system for near-infrared fluorescence image-guided surgery [8935-14]

P. Dorval, iCube Lab., Univ. de Strasbourg, CNRS (France) and Fluoptics (France);

N. Mangeret, S. Guillermet, Fluoptics (France); C. Righini, Institut Albert Bonniot (France), Univ. Joseph Fourier (France), and Univ. Hospital of Grenoble (France); G. Barabino, CHU Saint-Etienne (France); P. Rizo, CEA-LETI (France); P. Poulet, iCube Lab., Univ. de Strasbourg, CNRS (France)

8935 OG A novel multiwavelength fluorescence image-guided surgery imaging system [8935-15] D. Volpi, I. D. C. Tullis, A. Laios, Univ. of Oxford (United Kingdom); P. N. J. Pathiraja, Univ. of Oxford (United Kingdom) and Oxford Univ. Hospitals NHS Trust (United Kingdom); K. Haldar, Oxford Univ. Hospitals NHS Trust (United Kingdom); A. A. Ahmed, B. Vojnovic, Univ. of Oxford (United Kingdom)

$8935 \mathrm{OH} \quad 3 \mathrm{D}$ topography of biologic tissue by multiview imaging and structured light illumination [8935-16]

P. Liu, S. Zhang, Univ. of Science and Technology of China (China); R. XU, Univ. of Science and Technology of China (China) and The Ohio State Univ. (United States)

8935 Ol Image-guided plasma therapy of cutaneous wound [8935-17]

Z. Zhang, W. Ren, Z. Yu, S. Zhang, T. Yue, Univ. of Science and Technology of China (China); R. XU, Univ. of Science and Technology of China (China) and The Ohio State Univ. (United States)

8935 0J A goggle navigation system for cancer resection surgery [8935-18]

J. Xu, P. Shao, T. Yue, S. Zhang, H. Ding, J. Wang, Univ. of Science and Technology of China (China); R. XU, Univ. Of Science and Technology of China (China) and The Ohio State Univ. (United States)

$8935 \mathrm{OL}$ Towards femtosecond laser surgery guidance in the posterior eye: utilization of optical coherence tomography and adaptive optics for focus positioning and shaping [8935-20] A. Krüger, A. Hansen, B. Matthias, T. Ripken, Laser Zentrum Hannover e.V. (Germany)

RAMAN DEVICES AND METHODS

8935 OM Shifted excitation Raman difference spectroscopy using a dual-wavelength DBR diode laser at $671 \mathrm{~nm}[8935-21]$

M. Maiwald, J. Fricke, A. Ginolas, J. Pohl, B. Sumpf, G. Erbert, G. Tränkle, Ferdinand-BraunInstitut (Germany) and Leibniz-Institut für Höchstfrequenztechnik (Germany)

SCATTERING, REFLECTANCE, AND POLARIMETRIC TECHNIQUES

8935 OR Reflectance confocal microscopy of oral epithelial tissue using an electrically tunable lens [8935-26]

J. M. Jabbour, B. H. Malik, R. Cuenca, S. Cheng, J. A. Jo, Texas A\&M Univ. (United States);

Y.-S. L. Cheng, J. M. Wright, Texas A\&M Health Science Ctr. (United States); K. C. Maitland, Texas A\&M Univ. (United States) 
8935 OS Mueller polarimetry for the detection of cancers [8935-27]

E. Du, H. He, N. Zeng, Y. Guo, M. Sun, H. Ma, Tsinghua Univ. (China); S. Liu, M. Li, Huazhong Univ. of Science and Technology (China)

BIOSENSING AND IMAGING I

8935 OV IgG/anti-IgG immunoassay based on a turn-around point long period grating [8935-30] F. Chiavaioli, IFAC-CNR, Istituto di Fisica Applicata Nello Carrara (Italy); P. Biswas, Central Glass and Ceramic Research Institute (India); C. Trono, A. Giannetti, S. Tombelli, IFAC-CNR, Istituto di Fisica Applicata Nello Carrara (Italy); S. Bandyopadhyay, N. Basumallick, K. Dasgupta, Central Glass and Ceramic Research Institute (India); F. Baldini, IFAC-CNR, Istituto di Fisica Applicata Nello Carrara (Italy)

$8935 \mathrm{OW}$ The application of surgical navigation system using optical molecular imaging technology in orthotopic breast cancer and metastasis studies [8935-31]

C. Chi, Key Lab. of Molecular Imaging of Chinese Academy of Sciences (China);

Q. Zhang, Xidian Univ. (China); D. Kou, Chinese PLA General Hospital (China); J. Ye,

Y. Mao, Key Lab. of Molecular Imaging of Chinese Academy of Sciences (China); J. Qiu, J. Wang, Chinese PLA General Hospital (China); X. Yang, Y. Du, Key Lab. of Molecular Imaging of Chinese Academy of Sciences (China); J. Tian, Key Lab. of Molecular Imaging of Chinese Academy of Sciences (China) and Xidian Univ. (China)

8935 0X The optics inside an automated single molecule array analyzer [8935-32] W. McGuigan, Stratec Biomedical USA (United States); D. R. Fournier, Quanterix Corp. (United States); G. W. Watson, L. Walling, B. Gigante, Stratec Biomedical USA (United States); D. C. Duffy, D. M. Rissin, C. W. Kan, R. E. Meyer, T. Piech, M. W. Fishburn, Quanterix Corp. (United States)

$89350 Z$ Background fluorescence reduction and absorption correction for fluorescence reflectance imaging [8935-34]

F. Fantoni, L. Hervé, V. Poher, CEA-LETI (France); S. Gioux, Beth Israel Deaconess Medical Ctr. (United States); J. I. Mars, GIPSA Lab., Grenoble INP, Univ. Joseph Fourier, CNRS (France) and Univ. Stendhal (France); J. M. Dinten, CEA-LETI (France)

BIOSENSING AND IMAGING II

893510 Multispectral imaging of organ viability during uterine transplantation surgery [8935-35] N. T. Clancy, S. Saso, Imperial College London (United Kingdom); D. Stoyanov, Univ. College London (United Kingdom); V. Sauvage, Imperial College London (United Kingdom); D. J. Corless, Leighton Hospital (United Kingdom); M. Boyd, D. E. Noakes, The Royal Veterinary College (United Kingdom); M.-Y. Thum, The Lister Hospital (United Kingdom); S. Ghaem-Maghami, J. R. Smith, D. S. Elson, Imperial College London (United Kingdom)

893514 Implementation and evaluation of Google Glass for visualizing real-time image and patient data in the primary care office [8935-39]

G. L. Monroy, N. D. Shemonski, R. L. Shelton, R. M. Nolan, S. A. Boppart, Univ. of Illinois at Urbana-Champaign (United States) 
893516 Motion tracking to enable pre-surgical margin mapping in basal cell carcinoma using optical imaging modalities: initial feasibility study using optical coherence tomography [8935-42]

M. Duffy, King's College London (United Kingdom); T. J. Richardson, E. Craythorne,

R. Mallipeddi, Guy's and St Thomas' NHS Foundation Trust (United Kingdom); A. J. Coleman, King's College London (United Kingdom) and Guy's and St Thomas' NHS Foundation Trust (United Kingdom)

893517 Improved method to visualize lipid distribution within arterial vessel walls by $1.7 \mu \mathrm{m}$ spectroscopic spectral-domain optical coherence tomography [8935-43] M. Hirano, S. Tonosaki, T. Ueno, M. Tanaka, T. Hasegawa, Sumitomo Electric Industries, Ltd. (Japan)

\section{COHERENCE TECHNIQUES II}

8935 1B OCT-aided anastomosis platform study in the rodent model [8935-47]

Y. Huang, Johns Hopkins Univ. (United States); D. Tong, Johns Hopkins Univ. School of Medicine (United States) and Beijing Jishuitan Hospital (China); S. Zhu, Johns Hopkins Univ. School of Medicine (United States), Peking Union Medical College (China), and Chinese Academy of Medical Science (China); L. Wu, Z. Ibrahim, W. A. Lee, G. Brandacher, Johns Hopkins Univ. School of Medicine (United States); J. U. Kang, Johns Hopkins Univ. (United States)

8935 IC In vivo intra-operative breast fumor margin detection using a portable OCT system with a handheld surgical imaging probe [8935-48]

S. J. Erickson-Bhatt, R. Nolan, N. D. Shemonski, S. G. Adie, Univ. of Illinois at UrbanaChampaign (United States); J. Putney, D. Darga, Diagnostic Photonics, Inc. (United States); D. T. McCormick, AdvancedMEMS (United States); A. Cittadine, Diagnostic Photonics, Inc. (United States); M. Marjanovic, E. J. Chaney, G. L. Monroy, F. South, Univ. of Illinois at Urbana-Champaign (United States); P. S. Carney, Univ. of Illinois at Urbana-Champaign (United States) and Diagnostic Photonics, Inc. (United States); K. A. Cradock, Z. G. Liu, P. S. Ray, Carle Foundation Hospital (United States); S. A. Boppart, Univ. of Illinois at UrbanaChampaign (United States), Diagnostic Photonics, Inc. (United States), and Carle Foundation Hospital (United States)

\section{ENDOSCOPIC DEVICES AND METHODS}

8935 IE Spectral encoding enhances visual flexibility of surgical endoscopes [8935-50] C. Barsi, MIT Media Lab. (United States); A. Velten, MIT Media Lab. (United States) and Univ. of Wisconsin-Madison (United States); M. Lorrainy-Altoe, MIT Media Lab. (United States); A. Rehman, Sarasota Memorial Hospital (United States); R. Raskar, MIT Media Lab. (United States) 
8935 IF System for clinical photometric stereo endoscopy [8935-51]

N. J. Durr, G. González, D. Lim, Massachusetts Institute of Technology (United States) and Wellman Ctr. for Photomedicine, Harvard Medical School, Massachusetts General Hospital (United States); G. Traverso, Harvard Medical School, Massachusetts General Hospital (United States) and Massachusetts Institute of Technology (United States); N. S. Nishioka, Harvard Medical School, Massachusetts General Hospital (United States); B. J. Vakoc, Wellman Ctr. for Photomedicine, Harvard Medical School, Massachusetts General Hospital (United States); V. Parot, Massachusetts Institute of Technology (United States) and Wellman Ctr. for Photomedicine, Harvard Medical School, Massachusetts General Hospital (United States)

$89351 \mathrm{G}$ Evaluation of the three-dimensional endoscope system for assessing the gastrointestinal motility [8935-52]

K. Yoshimoto, K. Yamada, K. Watabe, M. Takeda, T. Nishimura, M. Kido, Osaka Univ. (Japan); T. Nagakura, Osaka Electro-Communication Univ. (Japan); H. Takahashi, Osaka City Univ. (Japan); T. Nishida, H. lijima, M. Tsujii, T. Takehara, Y. Ohno, Osaka Univ. (Japan)

\section{ADVANCED MEDICAL DEVICES AND TECHNIQUES}

$89351 \mathrm{~J}$ Development of a fiber based Raman probe compatible with interventional magnetic resonance imaging [8935-55]

P. C. Ashok, B. B. Praveen, Univ. of St. Andrews (United Kingdom); M. Rube, B. Cox, A. Melzer, Univ. of Dundee (United Kingdom); K. Dholakia, Univ. of St. Andrews (United Kingdom)

8935 IK Development of a multi-frequency diffuse photon density wave device for the characterization of tissue damage at multiple depths [8935-56]

D. Diaz, M. S. Weingarten, M. T. Neidrauer, J. A. Samuels, R. B. Huneke, Drexel Univ. (United States); V. L. Kuzmin, St. Petersburg Institute of Commerce and Economics (Russian Federation); P. A. Lewin, L. A. Zubkov, Drexel Univ. (United States)

8935 IL Development of multiwavelength excitation light source for autofluorescence and photodynamic diagnosis systems [8935-57]

N. Kenar, Chungnam National Univ. (Korea, Republic of) and Kocaeli Univ. (Turkey);

H. S. Lim, A. Mirzaaghasi, Chungnam National Univ. (Korea, Republic of)

$8935 \mathrm{iN}$ Continuous noninvasive in vivo monitoring of intravascular plasma volume and hematocrit changes during hemodialysis in humans: direct comparison with the CRIT-LINE [8935-59]

B. Deng, Syracuse Univ. (United States) and LighTouch Medical, Inc. (United States); E. Kastner, S. S. Narsipur, LighTouch Medical, Inc. (United States); J. Goodisman, Syracuse Univ. (United States); J. Chaiken, Syracuse Univ. (United States) and LighTouch Medical, Inc. (United States)

8935 IP Development of a baby friendly non-contact method for measuring vital signs: First results of clinical measurements in an open incubator at a neonatal intensive care unit [8935-61] J. H. G. M. Klaessens, M. van den Born, A. van der Veen, J. Sikkens-van de Kraats, F. A. M. van den Dungen, R. M. Verdaasdonk, VU Univ. Medical Ctr. (Netherlands) 
8935 iU A near-infrared fluorescence-based surgical navigation system imaging software for sentinel lymph node detection [8935-66]

J. Ye, C. Chi, Institute of Automation (China); S. Zhang, Northeastern Univ. (China); X. Ma,

J. Tian, Institute of Automation (China)

8935 IX Optical measurement system for preparation and after-OP-check of a hip joint endoprothetic implantation [8935-69]

R. Maschke, B. Lempe, Ch. Taudt, F. Rudek, T. Baselt, F. Basan, West Saxony Univ. of Applied Sciences (Germany); R. Grunert, Fraunhofer-Institut für Werkzeugmaschinen und Umformtechnik (Germany); P. Hartmann, West Saxony Univ. of Applied Sciences (Germany)

893520 Nature of autofluorescence in human serum albumin under its native, unfolding and digested forms [8935-72]

M. S., B. S. S. Rao, K. Satyamoorthy, K. K. Mahato, Manipal Univ. (India)

893526 Continuous noninvasive in vivo monitoring of intravascular plasma volume and hematocrit changes in response to blood removal and fluid replacement in a rat model [8935-78] B. Deng, LighTouch Medical, Inc. (United States) and Syracuse Univ. (United States); E. Kastner, SUNY Upstate Medical Univ. (United States); P. Dent, J. Goodisman, Syracuse Univ. (United States); J. Chaiken, LighTouch Medical, Inc. (United States) and Syracuse Univ. (United States)

893527 Multispectral tissue analysis and classification towards enabling automated robotic surgery [8935-79]

B. Triana, Children's National Medical Ctr. (United States); J. Cha, Johns Hopkins Univ. (United States); A. Shademan, A. Krieger, Children's National Medical Ctr. (United States); J. U. Kang, Johns Hopkins Univ. (United States); P. C. W. Kim, Children's National Medical Ctr. (United States)

893528 Photon-tissue interaction model for quantitative assessment of biological tissues [8935-80] S. Y. Lee, W. R. Lloyd, R. H. Wilson, M. Chandra, B. McKenna, D. Simeone, J. Scheiman, M.-A. Mycek, Univ. of Michigan (United States)

Author Index 


\title{
Conference Committee
}

\author{
Symposium Chairs
}

James G. Fujimoto, Massachusetts Institute of Technology

(United States)

R. Rox Anderson, Wellman Center for Photomedicine, Massachusetts General Hospital (United States) and Harvard School of Medicine (United States)

Program Track Chairs

Tuan Vo-Dinh, Fitzpatrick Institute for Photonics, Duke University (United States)

Anita Mahadevan-Jansen, Vanderbilt University (United States)

\section{Conference Chairs}

Tuan Vo-Dinh, Fitzpatrick Institute for Photonics, Duke University (United States)

Anita Mahadevan-Jansen, Vanderbilt University (United States)

Warren S. Grundfest, University of California, Los Angeles

(United States)

Conference Program Committee

Maurice C. Aalders, Forensic Technical Solutions (Netherlands)

Francesco Baldini, Istituto di Fisica Applicata Nello Carrara (Italy)

Jennifer K. Barton, The University of Arizona (United States)

Stephen A. Boppart M.D., University of Illinois at Urbana-Champaign (United States)

Gerald Grant, Duke University (United States)

Hong Liu, The University of Oklahoma (United States)

Laura Marcu, University of California, Davis (United States)

Mary-Ann Mycek, University of Michigan (United States)

Jianan Y. Qu, Hong Kong University of Science and Technology (Hong Kong, China)

Urs Utzinger, The University of Arizona (United States)

Georges A. Wagnières, Ecole Polytechnique Fédérale de Lausanne (Switzerland)

Christopher W. Woods M.D., Duke University (United States)

Pixuan 'Joe' Zhou, DMetrix, Inc. (United States) 
1 Fluorescence Systems

Tuan Vo-Dinh, Duke University (United States)

2 Global Health Technologies I

Tuan Vo-Dinh, Duke University (United States)

Pixuan 'Joe' Zhou, DMetrix, Inc. (United States)

3 Global Health Technologies II

Tuan Vo-Dinh, Duke University (United States)

Pixuan 'Joe' Zhou, DMetrix, Inc. (United States)

4 Treatment Modalities and Image-Guided Surgery

Warren S. Grundfest, University of California, Los Angeles (United States)

5 Raman Devices and Methods

Anita Mahadevan-Jansen, Vanderbilt University (United States)

6 Scattering, Reflectance, and Polarimetric Techniques

Kristen Maitland, Texas A\&M University (United States)

$7 \quad$ Biosensing and Imaging I

Francesco Baldini, Istituto di Fisica Applicata Nello Carrara (Italy)

8 Biosensing and Imaging II

Urs Utzinger, The University of Arizona (United States)

9 Coherence Techniques I

A. Claude Boccara, Institut Langevin (France)

10 Coherence Techniques II

Stephen A. Boppart M.D., University of Illinois at Urbana-Champaign (United States)

11 Endoscopic Devices and Methods

Urs Utzinger, The University of Arizona (United States)

12 Advanced Medical Devices and Techniques

Paul M. W. French, Imperial College London (United Kingdom) 


\section{Introduction}

This year's conference continues to explore diagnostic and surgical applications of a broad range of optical techniques, including fluorescent imaging methods, reflectance spectroscopy, diffuse optical spectroscopy, optical coherence tomography, Raman spectroscopy, and other advanced photonic methods. These investigations represent the state-of-the-art in their respective fields, and provide the reader with a snapshot of the most recent developments in optical imaging sciences for diagnostics and surgical guidance. This volume is not meant to be comprehensive. Rather, it presents focused research studies that are necessary for technology development and translation to clinical application. The studies in this volume range from basic science and engineering and modeling efforts to clinical investigations using recently created novel devices. It is important for the reader to place these achievements in context. The goal of many of these studies is to establish the feasibility of a particular approach or device. Demonstration of success does not guarantee clinical adoption of the technology. However, this volume demonstrates the dramatic progress that has been made over the last several years in using optical methods to extract information from tissue, and provide intraoperative guidance for surgical

procedures. This progress has been possible through collaborative efforts involving biomedical engineers, optical scientists from a range of disciplines, physicians, electrical and mechanical engineers, molecular biologists, and pharmacologists, among others. Government support, primarily through the NIH and the DOD, has been critical to the development and growth of these interdisciplinary teams. At the same time, several companies have been successful in developing opticalbased technologies for diagnostic systems and surgical guidance. This has encouraged additional investment in this growing area of research, which facilitates translation to clinical practice. As noted in last year's Foreword, "These papers illustrate the need for increased support of translational activities and development of academic, industry, and government partnerships to facilitate translation from proof of principle into clinical practice."

At the same time, continued support of basic science and preliminary investigations is critical to continue the growth and development of optical sciences and engineering. These studies provide the foundation for device development and new methods of surgical guidance. Before any new technology can be adapted for clinical use, it is essential to determine both the safety and efficacy of the technology, and demonstrate its operation in models and in animal models (where appropriate). Productive capacity is necessary for the conduct of clinical trials, since clinical trials cannot occur with one device. Therefore, collaboration and technology transfer to industry is an essential part of the technology development process. 
We hope that readers of this volume use the papers presented here to assess the state-of-the-art in biomedical optics for advanced biomedical and clinical diagnostic systems and surgical guidance systems. Further, we hope that these papers promote future investigations and serve as a guidepost to future studies.

Tuan Vo-Dinh Anita Mahadevan-Jansen Warren S. Grundfest 